AGROEGOSSISTEMASS

Núcleo de Meio Ambiente Universidade Federal do Pará Rua Augusto Corrêa, 01, Guamá Belém, Pará, Brasil https://periodicos.ufpa.br/index.php/agroecossistemas

Erika Kirsten Dobe Universidade Federal do Ceará ikabella2000@yahoo.com

Thiago Parente Chagas Universidade Federal do Ceará tparentechagas@yahoo.com.br

Francisco Carlos Barboza Nogueira

Universidade Federal do Ceará fcbarbozanogueira@hotmail.com

Recebido em: 2020-04-24 Avaliado em: 2020-09-04 Aceito em: 2020-09-18

\section{AVALIAÇÃO DE UM SISTEMA AGROALIMENTAR NO SEMIÁRIDO BRASILEIRO: UM OLHAR ECONÔMICO-ECOLÓGICO}

RESUMO: A implantação de um assentamento rural pelo Instituto Nacional de Colonização e Reforma Agrária INCRA representa a construção de um novo território para o agricultor e sua família, onde é possível implantar práticas sustentáveis de agricultura. A pesquisa foi desenvolvida para avaliar um agroecossistema composto por quatro assentados de um mesmo núcleo familiar, sendo que dois praticam agricultura e pecuária conforme a tradição da região, enquanto os outros dois seguem os conceitos agroecológicos da permacultura. Para avaliar o agroecossistema foi escolhido o método de Análise Econômico-Ecológica de Agroecossistemas desenvolvido pelas Articulação Nacional de Agroecologia e AS-PTA - Agricultura Familiar e Agroecologia. A criação de uma rede de suporte que levou a uma série de cursos e benefícios como projetos de plantio de frutíferas e capineira, alavancaram a produção do núcleo familiar do agroecossistema e proporcionaram maior autonomia às mulheres do assentamento. A entrada da linha de crédito Fomento Mulher através do INCRA foi uma das causas apontadas para essa mudança. Investimentos na irrigação da horta e na capineira através de empréstimos do AgroAmigo e do CrediAmigo foram decisivos para garantir a soberania alimentar do Núcleo de Gestão Social do Agroecossistema - NSGA. A implantação da mandala proporcionou o plantio de novas culturas de frutas, legumes e verduras, além da piscicultura. A diversificação de produtos trouxe um incremento na qualidade e segurança da alimentação do NSGA, abriu um leque maior de produtos comercializáveis, onde se destacam como fonte de renda cada vez mais crescente a venda de Tilápia e das hortaliças.

PALAVRAS-CHAVE: Assentamento Rural, Agroecologia, Agricultura Familiar, Mandala, Agroecossistema. 


\section{ASSESSMENT OF AN AGRIFOOD SYSTEM IN THE BRAZILIAN SEMIARID REGION: AN ECOLOGICAL-ECONOMIC VIEW}

ABSTRACT: The implementation of a rural settlement by the National Institute of Colonization and Agrarian Reform - INCRA represents the construction of a new territory for the farmer and their family, allowing for the adoption of sustainable farming practices. The purpose of the study was to assess an agroecosystem composed of four settlers belonging to the same family, wherein two practice agriculture and husbandry according to regional tradition, while the other two apply the agroecological concepts of permaculture. The method of Ecological-Economic Analysis of Agroecosystems developed by the National Articulation of Agroecology and AS-PTA - Family Agriculture and Agroecology was chosen to assess the agroecosystem. The creation of a support network led to a series of courses and benefits such as projects to plant fruit trees and forage grass that levered the production of the family's agroecosystem and provided the women with increased autonomy. One of the causes was a line of credit geared to the advancement of women (Fomento Mulher). Investments in irrigation of the vegetable garden and the grass field, through loans from AgroAmigo and CrediAmigo were decisive in guaranteeing the food sovereignty of the Agroecosystem Social Management Nucleus - NSGA. The implementation of the mandala allowed the cultivation of new crops of fruits, legumes, and leafy vegetables, in addition to pisciculture. Product diversification brought the NSGA an increase in food quality and security, and expanded the range of saleable products, where tilapia and vegetables stand out as an ever-greater source of income for the nucleus.

KEYWORDS: Rural settlement, Agroecology, Family farming, Mandala, Agroecosystem.

\section{EVALUACIÓN DE UN SISTEMA AGROALIMENTARIO EN LA REGIÓN SEMIÁRIDA BRASILEÑA: UNA VISIÓN ECONÓMICO-ECOLÓGICA}

RESUMEN: La implantación de un asentamiento rural por parte del Instituto Nacional de Colonización y Reforma Agraria - INCRA representa la construcción de un nuevo territorio para el agricultor y su familia, donde es posible implementar prácticas agrícolas sostenibles. La investigación se desarrolló para evaluar un agroecosistema compuesto por cuatro colonos del mismo núcleo familiar, dos de los cuales practican la agricultura y la ganadería de acuerdo con la tradición de la región, mientras que los otros dos siguen los conceptos agroecológicos de la permacultura. Para evaluar el agroecosistema, se eligió el método de Análisis Económico-Ecológico de Agroecosistemas desarrollado por la Articulación Nacional de Agroecología y AS-PTA - Agricultura familiar y agroecología. La creación de una red de apoyo que condujo a 
una serie de cursos y benefícios como proyectos de plantación de fruta y pasto impulsó la producción del núcleo familiar del agroecosistema y proporcionó una autonomía repentina para las mujeres en el asentamiento. La entrada de la línea de crédito Fomento Mulher a través de INCRA fue una de las causas señaladas para este cambio. Las inversiones en el riego de los huertos y pastizales a través de préstamos de AgroAmigo y CrediAmigo fueron decisivas para garantizar la soberanía alimentaria del Centro de Gestión Social del Agroecosistema - NSGA. La implementación del mandala proporcionó la plantación de nuevos cultivos de frutas y verduras, además de la piscicultura. La diversificación de productos trajo un aumento en la calidad y seguridad de los alimentos de la NSGA, abrió una gama más amplia de productos comercializables, ya que la venta de tilapia y verduras se destaca como una fuente de ingresos cada vez mayor.

PALABRAS CLAVES: Asentamiento rural, Agroecología, Agricultura familiar, Mandala, Agroecosistema.

\section{INTRODUÇÃO}

A reconquista da terra para um agricultor significa um novo começo de vida para ele e sua família. Representa o êxito do espaço reapropriado que passa a demandar novos desafios. Requer a criatividade e a coragem para uma nova adaptação ao território reconquistado, criando um novo espaço de vida, implantando novos costumes e novas práticas de fazer agricultura. É nessa direção que esse trabalho busca estudar a transformação da vida de famílias assentadas pelo Instituto Nacional de Colonização e Reforma Agrária INCRA através da implantação de práticas sustentáveis de agricultura.
O histórico do Assentamento Lagoa de Dentro, município de Itapipoca, Ceará, é semelhante ao que outros camponeses enfrentam no processo de conquista da terra (RODRIGUES, 2017). No início da década de 1940, a comunidade de Lagoa de Dentro acolheu em seu meio um homem que, posteriormente, conseguiu registrar as terras da Fazenda em seu nome. A partir daí, passou a exigir pagamento em mão de obra, em troca do direito das famílias continuarem a viver nas terras. Essa exploração durou décadas. Nos anos 2000, um parente desse homem comprou as terras da fazenda Lagoa de Dentro e ameaçou retirar os moradores definitivamente de suas 
terras. Entre outros incidentes, em 2007, o dono promoveu um desmatamento devastador em 110 hectares, o que corresponde a 10\% da área da fazenda. Nesse momento, a comunidade se organizou para lutar pelo que Ihe pertencia e que the foi usurpado.

Buscaram ajuda em outro assentamento rural. Através das orientações recebidas, formaram uma associação de moradores. Com a ajuda do sindicato dos trabalhadores rurais chegaram ao Instituto de Desenvolvimento Agrário do Ceará IDACE, onde iniciaram o processo de criação do assentamento, em 2008. Por existir registro em cartório, fugia da competência daquele órgão estadual a formalização do assentamento, pois a Constituição de 1988 limita ao âmbito nacional as desapropriações por interesse social para fins de reforma agrária (BERGAMASCO; NORDER, 1996). Consequentemente, O IDACE encaminhou, em 2015, o processo da Fazenda Lagoa de Dentro para o Instituto Nacional de Colonização e Reforma Agrária - INCRA.
A transformação da comunidade em um assentamento do INCRA constituiu um ponto de inflexão que levou a grandes transformações na vida dos assentados. Trouxe a oferta e captação de linhas de crédito relevantes para impulsionar a dinâmica produtiva. Surgiram oportunidades de treinamentos e cursos técnicos que alavancaram a produção dos núcleos familiares e proporcionaram uma autonomia súbita às mulheres do assentamento.

Estruturado para 21 famílias, atualmente há 18 famílias assentadas. Receberam a concessão de uso da terra, que é renovado a cada cinco anos. O INCRA disponibiliza cinco linhas de crédito subsidiadas aos assentados: Apoio inicial, Fomento Mulher, Fomento, Semiárido e Habitação. Os assentados até agora foram beneficiados pelas duas primeiras.

Esta pesquisa avaliou um agroecossistema localizado dentro do assentamento. Define-se como agroecossistema, um complexo sistema agrícola, social, econômico e 
ecológico, com limites em diversas dimensões (CONWAY, 1987). Para avaliar o agroecossistema foi escolhido o método de Análise EconômicoEcológica de Agroecossistemas desenvolvido pela Articulação Nacional de Agroecologia e AS-PTA Agricultura Familiar e Agroecologia (PETERSEN et al., 2017).

Esse método reconhece a importância de considerar de forma holística o funcionamento do agroecossistema, ou seja, a interação de natureza, economia e sociedade e procura "(...) restaura[r] a centralidade do trabalho nos processos de produção e reprodução social" (PETERSEN et al., 2017). Em especial, busca tirar da invisibilidade o trabalho da mulher. De acordo com esses autores, os modelos econômicos dominantes "situam o trabalho doméstico como alheio à esfera econômica, não atribuindo a essa atividade um papel e um lugar na produção da riqueza material" (PETERSEN et al., 2017).

O método procura lançar um olhar sobre as relações sociais e de poder que condicionam os processos de trabalho na apropriação, transformação, circulação e distribuição de riquezas socialmente produzidas na agricultura familiar. Esse método propõe, sobretudo, que as qualidades resultantes das estratégias de reprodução econômico-ecológica colocadas em prática pelo núcleo social sejam analisadas como atributos sistêmicos de sustentabilidade (PETERSEN et al., 2017).

Na presente análise foram levados em consideração os desafios trazidos pelo clima semiárido e as técnicas de convivência empregadas. Do agroecossistema analisado, uma agricultora, em particular, utiliza uma tecnologia social conhecida como sistema mandala. Tecnologia social é um termo que se refere a um mecanismo de erradicação de pobreza que "visa suplantar necessidades de um determinado grupo respeitando seus traços culturais, crenças e costumes; o que garante sua viabilidade e perenidade, e a caracteriza como inovação social." (COSTA et al., 2014, p.12). As tecnologias sociais de 
convivência com o semiárido buscam a

diminuição da miséria e aumento da produtividade, e como consequência, criam um freio para o êxodo rural em busca de vida melhor, que dificilmente se alcança com a fuga para os grandes centros urbanos (COSTA et al., 2014).

Ademais, a Economia Ecológica se fundamenta na interdisciplinaridade, colocando como elemento fundamental a equidade, a distribuição de renda, a ética e os processos culturais (VAN HAUWEREINREN, 1998). Assim, se apresenta como opção rica para analisar um agroecossistema com todos seus fluxos e subsistemas e interações entre homem e natureza, com devida importância não só à produtividade da terra e capacidade econômica, mas à história do lugar e das pessoas e definições mais abrangentes sobre o que é desenvolvimento e viver bem.

Essa pesquisa foi estruturada com os objetivos de se conhecer a construção social de um agroecossistema em um espaço territorial definido; estudar o agroecossistema como expressão material da agricultura familiar, focando o trabalho como processo de produção e reprodução social; e conhecer os efeitos ecológicos e econômicos de um agroecossistema em transição agroecológica.

\section{MATERIAL E MÉTODOS}

O estudo foi realizado no Assentamento Fazenda Lagoa de Dentro, que possui área de 1.149,74 hectares. A fazenda é localizada no município de Itapipoca, Ceará, com as seguintes Coordenadas Geográficas: Latitude: $03^{\circ} 15^{\prime} 12,16^{\prime \prime} \mathrm{S}$ e Longitude: 3940'49,3" O (Figura 1). O clima do município de Itapipoca é classificado como Tropical Quente Semiárido e Tropical Quente Semiárido Brando, com pluviosidade média anual de $1.130,4$ mm, concentrada nos meses de janeiro a maio, e temperatura média de $26^{\circ} \mathrm{C}$ a $28^{\circ}$ C (CEARÁ, 2017b). Sua vegetação caracteriza-se pela presença da caatinga arbustiva e arbórea densa. 
Figura 1. Mapa da localização da Fazenda Lagoa de Dentro, Itapipoca, Ceará.
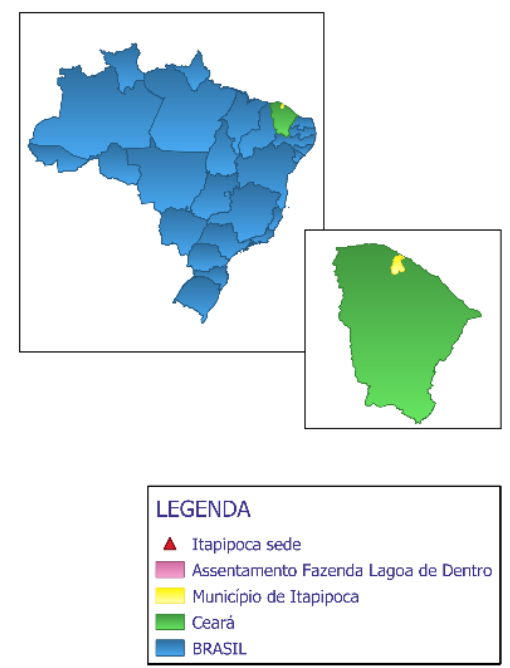

Cada família do Assentamento Lagoa de Dentro recebeu um lote individual correspondente a 20 ha. Outros 21 lotes foram demarcados ao longo da estrada estadual CE-85, com 6,80 ha, cada, que estão sem uso

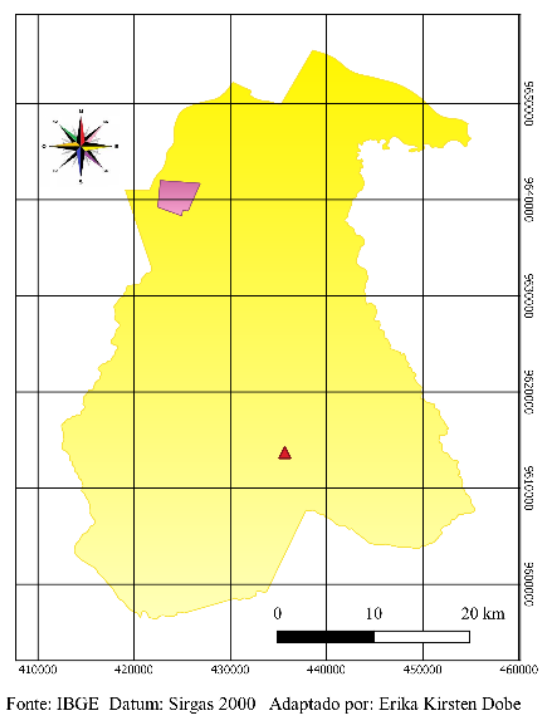

definido. Uma área de 180,43 ha foi demarcada para pastagem de uso coletivo, área de 47,45 ha como área institucional para construção de benfeitorias, e 233,68 ha para a Reserva Legal (Figura 2) (BRASIL, 2017).

Figura 2. Mapa de uso das terras do Assentamento Lagoa de Dentro, Itapipoca, Ceará.

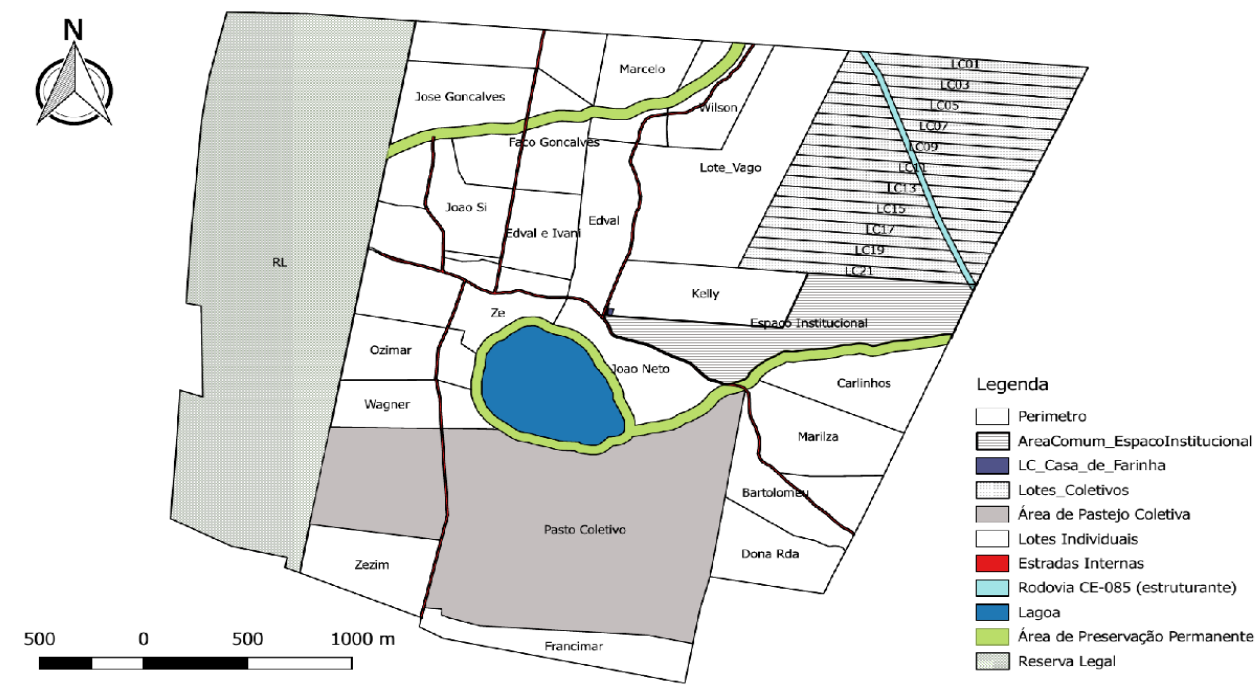

Fonte: BRASIL, 2017. 
Nessa análise, considerou-se um agroecossistema formado por quatro assentados de uma mesma família que autorizaram o uso dos nomes. 0 senhor Edval e esposa Lucimar praticam agricultura e pecuária tradicionais da região, enquanto a senhora Kelliany (Kelly), com a ajuda do esposo Gleison, inovou o modo de fazer agricultura, instalando nos últimos dois anos uma mandala, seguindo os conceitos agroecológicos da permacultura. Edval e Lucimar sempre viveram na região da Fazenda Lagoa de Dentro. Kelly e Gleison, no entanto, migraram para Fortaleza em 2010, mas sentiram falta da vida camponesa e em 2014 voltaram a residir na Fazenda Lagoa de Dentro.

As etapas da avaliação do método econômico-ecológico envolveram a identificação de um Núcleo de Gestão Social de Agroecossistema (NSGA), 4 entrevistas semiestruturadas presenciais conduzidas por um pesquisador e uma pesquisadora entre agosto e dezembro de 2019, construção de linha de tempo, identificação e modelização do sistema (Figura 3), em termos de insumos e produtos, trabalho e rendas, e a subsequente análise dos dados econômicos, sociais e ecológicos colhidos. Foi dado destaque para a identificação do trabalho em todos seus aspectos. Para efeitos de avaliação diacrônica, informações foram colhidas sobre dois anos: 2016, o primeiro ano efetivo como assentamento do INCRA, e 2019. O agroecossistema do NSGA é composto por pomar, pecuária e uma mandala agroecológica, sendo que esta última, para efeitos de modelagem, foi separada em seus subsistemas, e o agroecossistema foi subdividido da seguinte forma: pomar, horta, piscicultura e pecuária.

O método de análise econômicoecológico apresenta uma série de atributos sistêmicos a serem avaliados em relação ao agroecossistema, quais sejam: Autonomia, Responsividade, Integração Social e Equidade de Gênero/Protagonismo das Mulheres. 
Figura 3. Modelização básica do agroecossistema, seus subsistemas e suprassistemas.

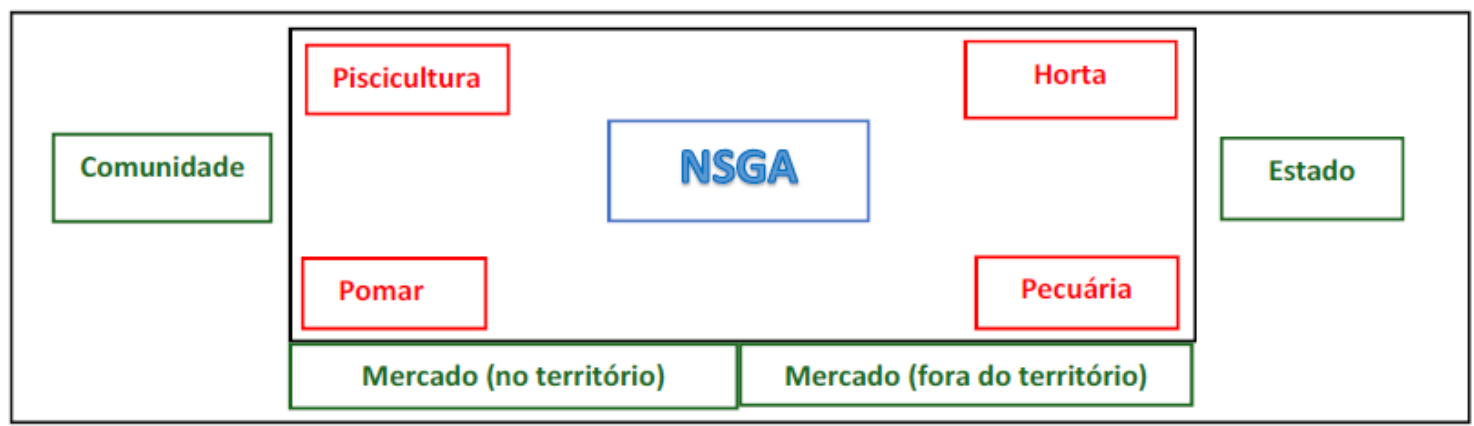

Fonte: Elaborado pelos autores

Para Petersen et al. (2017), o atributo autonomia resulta do balanço entre as condições internas e externas ao agroecossistema. Ou seja, os parâmetros estabelecidos são a) relacionados à base de recursos autocontrolada: objetos de trabalho, instrumentos de trabalho e a força de trabalho do núcleo e b) relacionados a externalização ou mercantilização das atividades de reprodução. $\bigcirc$ atributo Responsividade é relacionado à capacidade do NSGA responder às mudanças fora de seu controle, seja no âmbito social, econômico ou ambiental, e contempla as seguintes qualidades: estabilidade, flexibilidade, resistência e resiliência do NSGA. Considera-se elementos naturais e artificiais, como a biodiversidade, fertilidade do solo, estoque vivo e de insumos, banco de sementes, bombas d'água, sistema de irrigação e a diversidade de mercados e de rendas (PETERSEN et al., 2017). O agroecossistema deve ser analisado a partir dos diferentes vínculos que o NSGA estabelece com o ambiente político-institucional, ou seja, a comunidade, o mercado e o Estado. Assim, o atributo Integração Social avalia as relações não-mercantis do NSGA no âmbito social, gestão de bens comuns e reciprocidade (PETERSEN et al., 2017). A agroecologia tem o potencial de empoderar as mulheres, quando adequadamente concebidos e gerenciados, no entanto poucos estudos nessa área focam nessa questão (PARMENTIER, 2014). Portanto, o atributo equidade de gênero/protagonismo das mulheres 
propõe avaliar as relaç̃̃es sociais de gênero no âmbito do NSGA e diagnosticar as práticas de opressão que as mulheres muitas vezes sofrem na agricultura familiar além de mostrar a sobrecarga delas em termos de trabalho (PETERSEN et al., 2017).

\section{RESULTADOS E DISCUSSÃO}

AUTONOMIA

Em 2016, a produção do agroecossistema consistia no plantio de mandioca, milho e feijão, a venda de castanha de caju, e a criação de bovinos, carneiros, porcos e galinhas. Desde então, houve algumas modificações que aumentaram significativamente a autonomia do NSGA. A liberação das linhas de crédito, apoio inicial e fomento mulher, e acesso a cursos de capacitação possibilitaram melhoras nas práticas agrícolas e a construção da mandala agroecológica da Kelly, em 2017 (Figura 4). Essa mandala, atualmente, produz uma diversidade grande de cultivos, como coentro, cebolinha, pimentão, pimenta de cheiro, tomate cereja, banana e mamão, e plantas aromáticas e medicinais, o ano inteiro.
A mandala é uma tecnologia social com os seguintes atributos: reduz a dependência em insumos externos ao agroecossistema, fornece um microclima ameno com uma diversidade de cultivos, utiliza mais racionalmente a água, é sustentável e produz em harmonia com a natureza (MALVEZZI, 2007; MESIANO; DIAS, 2008). A mandala do NSGA proporciona uma biodiversidade substancial. A umidade, a fertilidade do solo, a cor vibrante e a temperatura mais amena apresentam um contraste marcante com a vegetação nativa que a cerca. Kelly relatou um aumento na fauna nativa desde a instalação da mandala, como pássaros que não se via há muito tempo e um aumento em insetos, mais notadamente, abelhas.

De acordo com Altieri (2004), "Quando a biodiversidade é restituída aos agroecossistemas, numerosas e complexas interações passam a estabelecer-se entre o solo, as plantas e os animais." (p. 24) Lima e GamarraRoja (2017), em estudo sobre o sistema mandala, também identificaram o benefício do equilíbrio ecológico que 
resulta do aumento da Como apontado por Lima e Gamarraagrobiodiversidade. Além de Rojas (2017), as hortícolas têm uma quantidade de alimento, a mandala elevada demanda hídrica, portanto não melhorou também a qualidade fazem parte da alimentação tradicional nutricional do alimento da família. do agricultor no semiárido.

Figura 4. Atributo Autonomia do agroecossistema, para os anos 2016 e 2019.

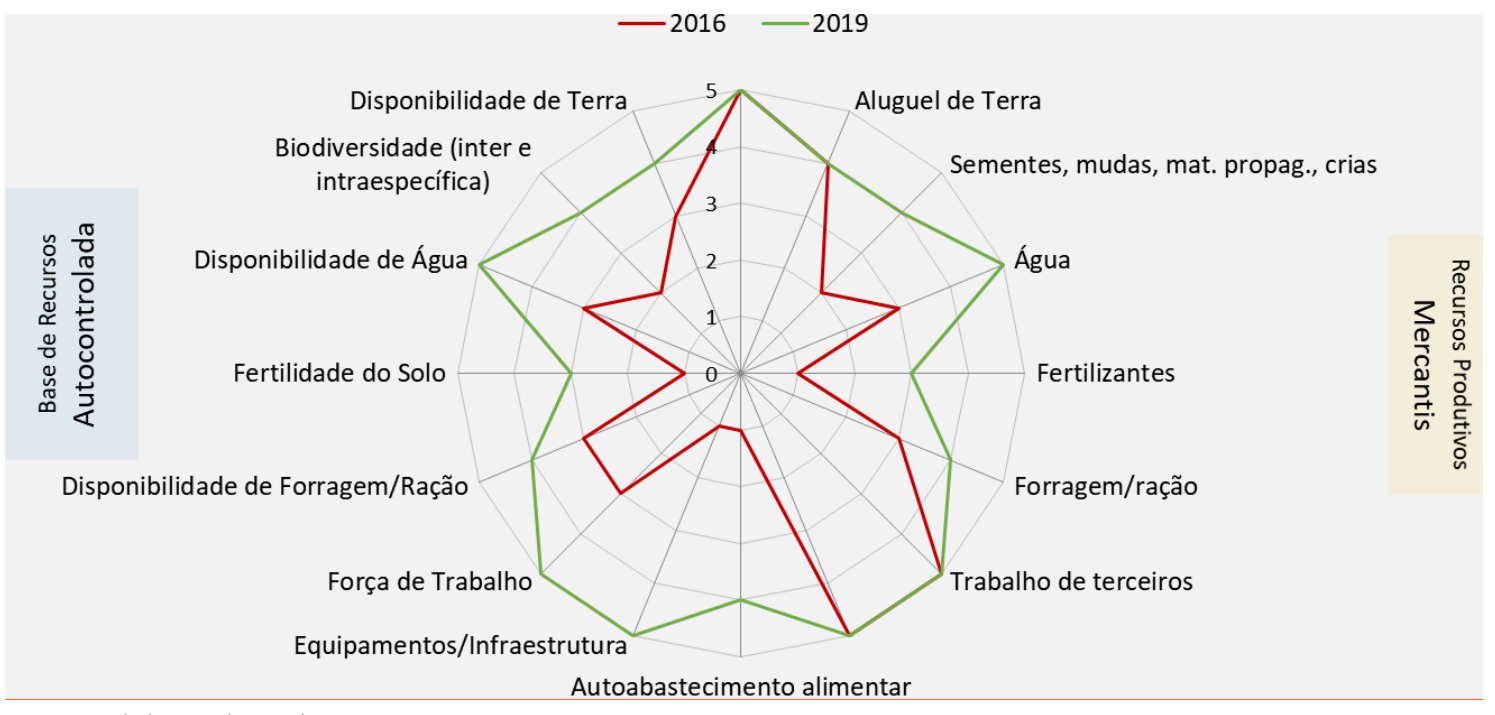

Fonte: Elaborado pelos autores.

assentamento disponibiliza uma área coletiva ampla de pasto. Por ser semiárido, há limitações de forragem na época de seca; os animais do NSGA recebem suplemento de ração. Anualmente, na época da chuva, o gado é levado para pasto no sertão, durante 4 meses, permitindo engordar os animais, enquanto o pasto da fazenda se recupera.

Em 2019, receberam um projeto da Empresa de Assistência Técnica e
Extensão Rural do Ceará - EMATERCE, para implantação de uma capineira, que deve proporcionar um incremento na alimentação dos rebanhos. No final de 2019, com empréstimos do Agroamigo e do Crediamigo, investiram na irrigação da horta e da capineira.

A utilização de recursos locais diminui os custos de produção viabilizando assim as tecnologias agroecológicas (ALTIERI, 2004). A 
maioria do material propagativo (sementes, tubérculos, manivas) é produzido dentro do NSGA, ou conseguido da casa de sementes da comunidade. No entanto, alguns insumos ainda precisam ser comprados. As sementes de coentro e a ração complementar dos animais são adquiridas no mercado local. Os alevinos também precisam ser comprados. Além disso, o solo onde foi instalada a mandala é de textura arenosa e poroso o que contribui para a lixiviação dos nutrientes essenciais às plantas. Por isso a Kelly necessita de esterco em maiores quantidades do que há disponível na fazenda. Esterco é comprado para fazer a compostagem, utilizando mão de obra do próprio assentamento para ensacar o esterco a preço menor. Isso representa uma economia em torno de $\mathrm{R} \$ 900$ ao ano e ajuda a manter o dinheiro dentro da comunidade.

O NSGA conseguiu a instalação de um poço profundo para a comunidade, fato que aumentou significativamente a segurança hídrica, uma vez que antes dependia apenas da captação da água pluvial para todas as suas necessidades.

O poço foi uma conquista decisiva, porque a insegurança hídrica é um dos mais importantes fatores limitantes da agricultura familiar no semiárido. Como pontuado por Lima e Gamarra-Rojas (2017):

As relações econômicas
historicamente construídas nos
sistemas de produção da região
fizeram com que os cultivos
sempre estivessem subjugados
aos grandes animais. As limitadas
reservas de água são disputadas e
direcionadas, primeiro para
consumo humano, depois, aos
animais. (p.186-187)

No entanto, o poço traz um gasto a mais com a conta de energia do motor e uma dependência maior em energia de fonte externa. Para aumentar a autossuficiência do NSGA, fontes de energias alternativas devem ser cogitadas.

\section{RESPONSIVIDADE}

Em relação ao acesso do NSGA a mercados, as vendas são feitas na vizinhança e em três localidades próximas. A mandala gera renda com a venda de coentro, cebolinha, tomate cereja, pimenta de cheiro, pimentão e 
tilápias (Figura 5). Dessa forma, segue a filosofia do Projeto Mandalla que é, primeiro, promover a autossuficiência da família e em seguida viabilizar "... empreendimentos produtivos e integrados ao meio ambiente..." (CEARÁ, 2017a, p.2). Lima e Gamarra-
Rojas (2017) em seu estudo de caso sobre uma mandala em Quixeramobim apontam a importância de diversificação de rendas, como das entradas semanais das vendas de hortaliças, na estabilidade da família.

Figura 5. Atributo Responsividade, dos anos 2016 e 2019.

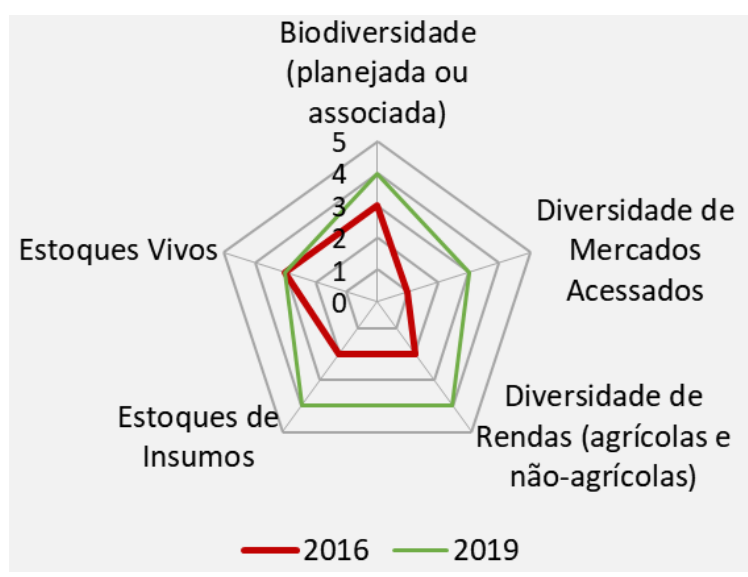

Fonte: Elaborado pelos autores.

O NSGA também começou a vender "dindin" (denominação regional para sucos congelados em saquinhos plásticos para serem consumidos como sorvete). Ademais, Dona Lucimar investiu numa despolpadora e em outubro de 2019 iniciou a venda de polpa de caju, acerola e murici. Os peixes normalmente são retirados pelos clientes na fazenda mesmo. Há um projeto de expandir a produção de batata doce, macaxeira, maxixe, banana e mamão para venda, sendo que hoje são produzidos somente para autoconsumo. A agroecologia é uma abordagem que privilegia a produção local, suprindo as necessidades dos mercados locais e assim diminuindo as necessidades altas de energia para transportar alimento por longas distâncias (ALTIERI; TOLEDO, 2011). 
Mandioca, um cultivo muito importante e tradicional para o NSGA, do qual produzem farinha e goma, em 2019 só foi plantada para autoconsumo porque a área onde antes era cultivada foi cedida a Kelly para a instalação da mandala. Em 2018, a plantação da mandioca foi feita entre as fileiras do pomar, mas em 2019, o espaço já não era mais adequado. Um desafio do NSGA foi não receber autorização para fazer a broca de uma área nova para plantio da mandioca porque a Superintendência Estadual do Meio Ambiente - SEMACE não liberou a queima na região. Vale salientar que no NSGA há vários anos não se utiliza mais a queima no preparo das terras para cultivo. Em 2016, a produção da farinha de mandioca rendeu ao NSGA R\$ 1.400,00. Em 2019, não houve renda com a venda desse produto.

O ano de 2019 foi de "seca verde", ou seja, a chuva foi concentrada (tempo) com longos intervalos (espaço) e prejudicou todos os cultivos sazonais tradicionais. As safras de feijão e de milho, ambas para autoconsumo, tiveram rendimentos muito baixos.
Parmentier (2014) define resiliência como a tendência de um sistema reter sua estrutura organizacional e produtividade após sofrer alguma perturbação. Apesar de vários contratempos em relação aos animais em 2019, a manutenção do rebanho continuou a proporcionar uma estabilidade e garantia alimentar ao NSGA, providenciando leite, carne e ovos o ano inteiro para a família. Em 2016, Lucimar, que se responsabiliza pela criação dos animais, experimentou introduzir a criação de porcos de raça, pela possibilidade de abate precoce. No entanto, ela julgou o custo/benefício dessa atividade economicamente inviável e voltou a criar somente porcos comuns. Estimaram que o rebanho em 2016 contava com 18 porcos. No final de 2019 esse número estava em 12. Para esse ano, relataram o autoconsumo de dois porcos e a venda de outros dois.

Em 2019, houve uma perda de ovinos e de galinhas devido a uma epidemia viral na região. De 25 galinhas que haviam comprado, todas foram perdidas, restando oito galinhas. 
Das 40 ovelhas que mantinham em 2016, esse número havia caído para 18, até o final de 2019. Já o rebanho de bovino, com o investimento da Dona Lucimar em gado (Fomento-mulher), contabilizava 16 cabeças, em 2019, o dobro do que mantinham em 2016.

Policultura, rotação de cultivos, utilização de sementes crioulas, inimigos naturais de pragas, de compostagem e adubação verde são maneiras de alcançar sustentabilidade e resiliência (ALTIERI; TOLEDO, 2011). Essas práticas são utilizadas na mandala. Um canteiro plantado com coentro, em seguida é plantado com cebolinha e depois tem um período de descanso. Onde possível, fazem uso de sementes crioulas ou material propagativo produzido dentro do agroecossistema. Kelly procura soluções agroecológicas aos problemas eventuais que aparecem.

É marcante a maneira em que os membros do NSGA respondem aos problemas que aparecem e trabalham juntos para buscar soluções. Percebese que além de resolver a crise no momento, buscam maneiras de evitar que os problemas se repitam. Estão abertos a inovações que possam trazer melhorias para a vida.

\section{INTEGRAÇÃO SOCIAL}

O NSGA traça seus laços às terras da Fazenda Lagoa de Dentro desde o ano 1918, portanto existe um senso de comunidade forte entre eles e os outros assentados, sendo que das 18 famílias atuais, 15 são descendentes diretas dos primeiros moradores (BRASIL, 2017).

envolvimento dos membros do NSGA na associação tem sido significativo desde o início em 2017, sendo que a Lucimar, mãe da Kelly, foi a primeira presidente da associação enquanto a Kelly é a presidente atual.

Desde a oficialização do assentamento, os membros do NSGA participam crescentemente de oficinas, cursos de capacitação, reuniões governamentais, conferências, constroem relacionamentos com diversos órgãos governamentais em todos os níveis, recebem assistência técnica e formam parcerias para trocas de saberes. 
O interesse intenso da Kelly, ao participar de um curso promovido pela EMATERCE, resultou em um convite para fazer um intercâmbio no Projeto Mandalla em 2017 que incluiu treinamento de instalação e cultivo da mandala. Foi nesse estágio que a Kelly desenvolveu seu conhecimento sobre noções agroecológicas e aprendeu a fazer compostagem e biofertilizante. Nunca saiu o financiamento previsto para a construção, mas Kelly juntou o investimento necessário através de linhas de crédito e instalou a mandala, com o suporte e apoio da família, que tem sido crucial para o sucesso do empreendimento.

Para ser sustentável, há uma necessidade de ir além do agroecossistema e pensar em termos de ações coletivas, coordenando com atores diferentes (PARMENTIER, 2014). Neste sentido, a Kelly insiste em estar sempre disponível para mostrar o trabalho que ela desenvolve com a mandala porque acredita fortemente na importância da agroecologia, sem falar do benefício da reciprocidade. Foi através dessa construção de relacionamentos que a associação de moradores conseguiu a doação da casa de sementes do assentamento e o poço profundo para o assentamento.

Como apontado anteriormente, o INCRA disponibiliza aos assentados linhas de crédito. Da primeira, de apoio inicial, $70 \%$ foi utilizada pela comunidade, em comum acordo, para cercar o perímetro do assentamento (BRASIL, 2017).

A agroecologia se baseia na participação e engajamento com a comunidade onde se vive ("community-oriented approaches") (ALTIERI; TOLEDO, 2011). Um dos objetivos é o fortalecimento não só da família, mas da comunidade como um todo (ALTIERI, 2004), e está claro que esse também é um princípio abraçado pelo NSGA e pela comunidade da Fazenda Lagoa de Dentro como um todo. A comunidade mantém uma cultura de reciprocidade em termos de trabalho, insumos e produtos (Figura 6). E essa reciprocidade dentro da comunidade fortalece o próprio núcleo de gestão. Tem reunião mensal do conselho da associação e reunião mensal geral, além da reunião mensal em Itapipoca a qual a Kelly, como presidente da associação, precisa participar. 
Os sábados do mês de maio são dedicados ao trabalho coletivo dos homens na restauração das estradas internas do assentamento e o mês de julho tem a farinhada, produção coletiva da farinha e goma de mandioca, onde todos participam do trabalho, homens e mulheres.

Em termos de apropriação da riqueza produzida no agroecossistema, o NSGA vende sua produção da horta e os peixes na vizinhança e nas localidades próximas. Em 2019, acrescentaram as atividades de venda de polpa e "dindin" na vizinhança. Para a venda da castanha de caju e da farinha, no entanto, é necessária a utilização de atravessador.

Figura 6. Atributo Integração Social para os anos 2016 e 2019.

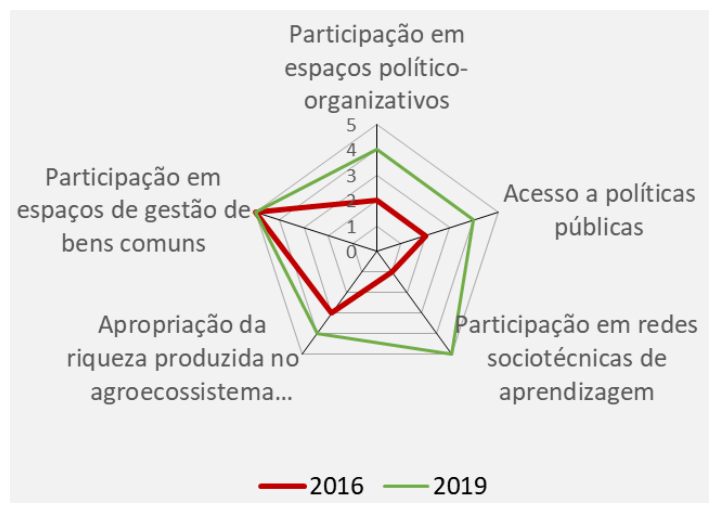

Fonte: Elaborado pelos autores.

EQUIDADE DE GÊNERO E causas apontadas pela mudança, mas PROTAGONISMO DAS MULHERES

o protagonismo significativo das

Na Figura 8 foi demonstrado que mulheres na luta pelo direito à terra e houve, entre 2016 e 2019, uma - acesso aumentado a cursos de mudança radical em termos da capacitação certamente tiveram um autonomia das mulheres em termos de participação nas decisões que afetam o agroecossistema e no âmbito coletivo. A entrada da linha de crédito Fomento Mulher através do INCRA foi uma das grande papel.

Ficou claro nas entrevistas que a jornada das mulheres (Figura 8) é muito mais exigente do que dos homens. Os deveres diários dos subsistemas da horta, do 
pomar, dos peixes e da pecuária são das mulheres de modo geral, sendo os homens auxiliadores nestas tarefas. No entanto, os trabalhos domésticos de roupa, fogão, limpeza e cuidados com crianças recaem também em cima das mulheres, quase em sua totalidade. Acrescenta-se a isso o fato que, no NSGA analisado, as mulheres são as maiores protagonistas na organização da comunidade. Participações em cursos também têm sido maior por parte das mulheres.

Figura 7. Equidade de gênero/protagonismo das mulheres, para os anos 2016 e 2019.

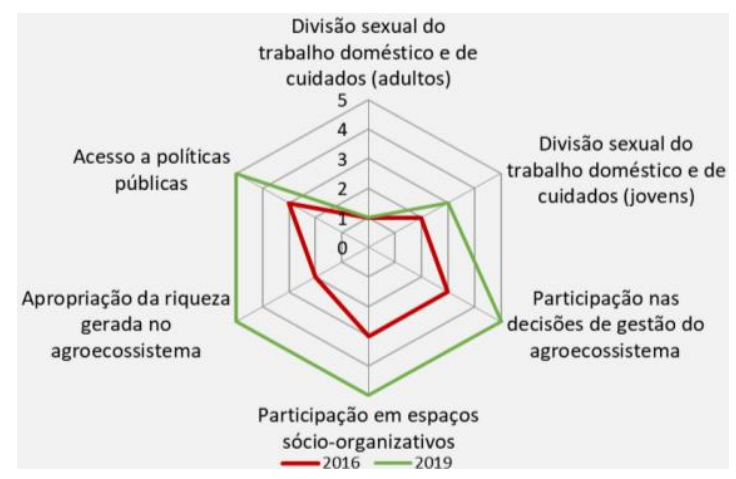

Fonte: Elaborado pelos autores.

A política de assentamentos no Brasil, como a do Projeto Mandalla no Ceará, visa fortalecer a autonomia e protagonismo da camponesa (FARIAS JR, 2019; BRASIL, 2020). Embora a mandala seja da Kelly, ela sente que tem impactado de forma rápida e significativa a autonomia das outras mulheres da família e da comunidade, que a princípio eram céticas. O protagonismo maior das mulheres foi aceito e é incentivado pelos membros do NSGA.

Figura 8. Repartição do tempo de trabalho por gênero e esfera de trabalho ( 8h/dia).

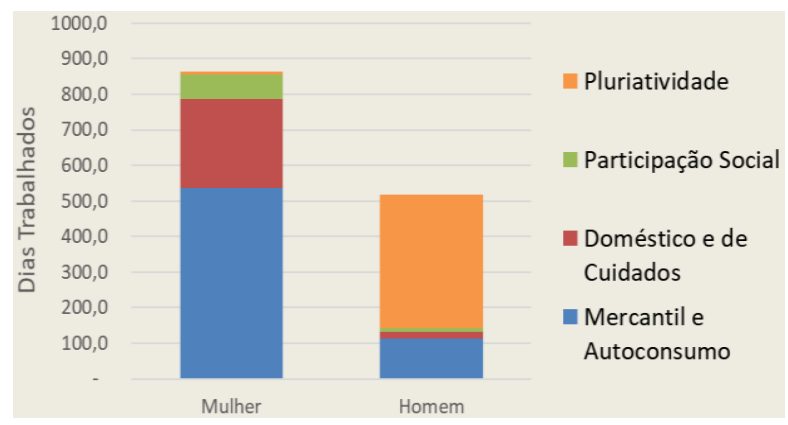

Fonte: Elaborado pelos autores. 
SÍNTESE DOS ATRIBUTOS SISTÊMICOS

Na Figura 9 é possível observar a evolução diacrônica entre 2016 e 2019 dos atributos estudados no NSGA. Como foi mostrado acima, o atributo Autonomia viu melhora principalmente devido ao acesso a água, aumento de biodiversidade e fertilidade. A maior contribuição para a melhora em Responsividade veio da diversidade de mercados e de rendas. A Integração Social do NSGA foi alavancada pelo acesso expandido a políticas públicas e cursos. E por fim, o atributo de equidade de gênero viu uma melhora generalizada em todas as dimensões consideradas com notável exceção para a divisão sexual de trabalho doméstico.

Figura 9. Síntese dos atributos sistêmicos do NSGA para os anos 2016 e 2019.

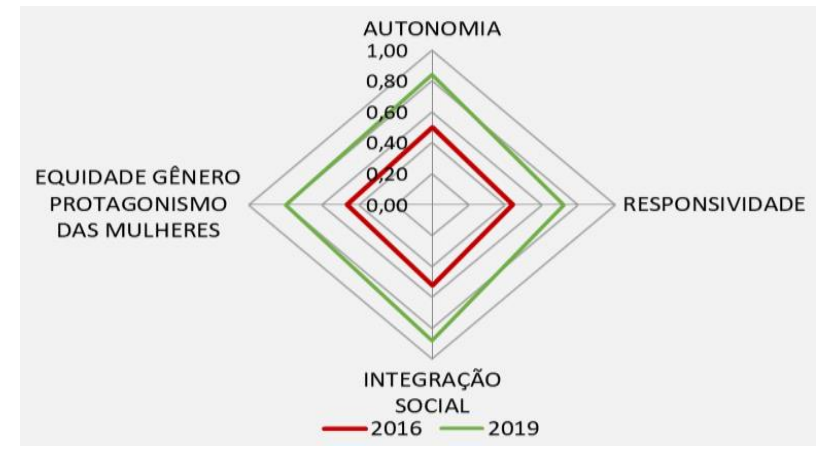

Fonte: Elaborado pelos autores.

\section{ECONOMIA DO NSGA}

O enfoque desse estudo, além de ecologicamente contextualizado, visa restaurar o trabalho como eixo central da atividade econômica, sem separação em esferas de trabalho produtivo e reprodutivo, uma vez que um não se desenvolve sem o outro (PETERSEN et al., 2017). É importante considerar que o funcionamento do agroecossistema depende não só da produção econômica, mas também da reprodução social, econômica e ecológica. Baseado em entrevistas e observações em campo, é notável a rápida evolução do NSGA como consequência das inovações nos aspectos socioeconômicos. 
Em 2016, o plantio do agroecossistema ainda se baseava na agricultura tradicional da região onde as culturas implantadas eram focadas no plantio de mandioca, milho, feijão e caju, totalmente dependente do período de chuvas para o sucesso do cultivo. Além disso, merece destaque a criação de galinhas, gado, suínos, caprinos e ovinos. Nota-se que a atividade agrícola proporcionava pouca segurança alimentar. A partir de meados de 2016, como discutido anteriormente, houve uma evolução na forma de plantar e o NSGA começou a implantar atividades mais sustentáveis, como por exemplo, a mandala.

A mandala tornou viável o plantio de novas culturas de frutas, legumes e verduras, além da piscicultura. Tais novidades deram um incremento substancial na produção e abriu um leque maior de produtos comercializáveis, pois se destacam como fonte de renda cada vez mais crescente a venda de tilápia e das hortaliças. Diferentemente dos produtos antes cultivados (castanha, farinha e goma de mandioca, milho), a produção da mandala não é sazonal. No entanto, o lucro que Kelly obtém da mandala ela investe quase toda de volta na horta, em ampliação da área de plantio e outras melhorias.

$\mathrm{Na}$ análise de produtos do agroecossistema, alguns comercializados e outros só para autoconsumo, inclui-se hortaliças, peixes, castanhas, gado, cabras, porcos, carneiros, galinha, uma variedade de frutas, farinha de mandioca, polpas de frutas, ovos, dindin e leite. Ao todo, estima-se que o NSGA gerou renda agrícola para o ano 2019 em torno de $\mathrm{R} \$ 27.500$, considerando vendas e autoconsumo, deduzido os custos.

Tabela 1. Composição de renda em 2019 em valores absolutos e em porcentagem.

\begin{tabular}{lll}
\hline 1 - Rendas Agrícolas & $\mathrm{R} \$ 27.555,00$ & $54 \%$ \\
\hline 1.1 Monetárias & $\mathrm{R} \$ 18.541,00$ & $67 \%$ \\
1.2 Não-monetárias & $\mathrm{R} \$ 9.014,00$ & $33 \%$ \\
2 - Rendas Não Agrícolas & $\mathrm{R} \$ 23.465,00$ & $46 \%$ \\
2.1 - Pluriatividade & $\mathrm{R} \$ 14.250,00$ & $61 \%$ \\
2.2 - Transferência de Renda & $\mathrm{R} \$ 9.215,00$ & $39 \%$ \\
\hline 3 - Renda Familiar Total & $\mathrm{R} \$ 51.020,00$ & $100 \%$ \\
\hline Fonte: elaborado pelos autores. & &
\end{tabular}


A participação das mulheres na segundo a lógica da reprodução geração de renda é significativa econômico-ecológica de um NSGA quando se calcula o valor do trabalho (Tabela 2).

Tabela 2. Repartição da renda por esfera de trabalho e por gênero.

\begin{tabular}{lccc}
\hline Esferas de Ocupação & Total Mulheres & Total Homens & Total Geral \\
\hline Mercantil e Autoconsumo & $15.814,39$ & $4.125,49$ & $19.939,88$ \\
Doméstico e de Cuidados & $8.594,78$ & 515,69 & $9.110,46$ \\
Participação Social & $1.890,85$ & 343,79 & $2.234,64$ \\
Pluriatividade & 206,27 & $10.313,73$ & $10.520,01$ \\
\hline Total & $26.506,30$ & $15.298,70$ & $41.805,00$ \\
\hline
\end{tabular}

Fonte: elaborado pelos autores.

Em termos de rendas não-agrícolas (Tabela 3), as mulheres do NSGA recebem auxílio do governo através dos programas Bolsa Família e Mais Infância e Gleison trabalha de carteira assinada, recebendo salário e vale alimentação.

Fatores como suprimento de água, diversificação da produção, capacitação da mão de obra e localidade próxima. consequente aperfeiçoamento de técnicas agrícolas são fundamentais para se trabalhar o solo do agroecossistema em questão. O NSGA tem conseguido investir em melhorias e tem planos para diversificar os produtos comercializados, com a possível abertura de uma quitanda numa

Tabela 3. Rendas não agrícolas no agroecossistema.

\begin{tabular}{cllll}
\hline & Unidade & Valor Unitário & Quantidade & \\
\hline $\begin{array}{c}\text { Pluriatividade } \\
\text { emprego Gleison }\end{array}$ & mensal & 1000,00 & 13 & $14.250,00$ \\
dindin - iniciou em & unidades & 0,50 & 2500 & $13.000,00$ \\
$\begin{array}{c}\text { Out/19 } \\
\text { Transferências de Renda }\end{array}$ & & & $1.250,00$ \\
bolsa família Kelly & mensal & 130,00 & 13 & $9.215,00$ \\
mais infância & mensal & 85,00 & 12 & $1.690,00$ \\
vale alimentação & mensal & 450,00 & 12 & $1.020,00$ \\
bolsa família Lucimar & mensal & 85,00 & 13 & $5.400,00$ \\
\hline
\end{tabular}

Fonte: elaborado pelos autores. 


\section{CONCLUSÃO}

A reconquista da terra mudou a vida dos antigos moradores da fazenda Lagoa de Dentro. A intermediação do INCRA na criação do Assentamento e na disponibilização de linhas de crédito subsidiadas foi decisiva na transformação da vida dos assentados e favoreceu à implantação de práticas sustentáveis de agricultura.

A evolução do núcleo familiar do agroecossistema em termos de visibilidade e valorização do trabalho das mulheres é franca e merece destaque. A causa apontada foi a criação de uma rede de suporte que levou a uma série de cursos e benefícios, alavancando a produção do NSGA e proporcionando uma autonomia súbita às mulheres. No entanto, as mulheres continuam tendo uma jornada significativamente mais dura do que os homens, uma vez que as responsabilidades domésticas recaem quase em sua totalidade sobre elas.

Uma das características mais notáveis é a resiliência: a maneira que a família se une para enfrentar os desafios. A mandala com piscicultura proporcionou um incremento enorme na biodiversidade, trazendo de volta à região fauna que havia desaparecido. Investimentos na irrigação foram decisivos para garantir a soberania alimentar e a diversificação de produtos melhorou a qualidade e segurança da alimentação do NSGA, abriu um leque maior de fontes de renda, com a venda de tilápia, hortaliças, polpas e dindin. No entanto, mesmo com melhores perspectivas financeiras, o foco do NSGA continua sendo produzir em harmonia com a natureza e a comunidade como um todo.

\section{REFERÊNCIAS}

ALTIERI, M.A. Agroecologia: a dinâmica produtiva da agricultura sustentável. 4.ed. - Porto Alegre: Editora da UFRGS, 2004.

AlTIERI, M.A.; TOLEDO, V.M. The agroecological revolution in Latin America: rescuing nature, ensuring food sovereignty and empowering peasants. Journal of Peasant Studies, v. 38, n. 3, p. 587-612, 2011.

BERGAMASCO, S. M. P. P.; NORDER, L. C. A. O que são Assentamentos Rurais. São Paulo, Ed. Brasiliense, 1996.

BRASIL. Instituto Nacional de Colonização e Reforma Agrária. 
CAPACITAÇÃO EM GESTÃO E PLANEJAMENTO ASSENTAMENTO LAGOA DE DENTRO- ITAPIPOCA/CE. Fortaleza: 2017.

BRASIL. Instituto Nacional de Colonização e Reforma Agrária. Reforma Agrária. Disponível em: http://www.incra.gov.br/pt/reformaagraria.html. Acesso em: 05 abr. 2020

CEARÁ a. Ematerce. Projeto De Produção Integrada Mandalla Módulos I e II. Fortaleza: Governo do Estado do Ceará, 2017. 70 p.

CEARÁ b. Secretaria do Planejamento e Gestão. Instituto de Pesquisa e Estratégia Econômica. Perfil básico municipal: Itapipoca. Fortaleza, IPECE, 2017.

CONWAY, G.R. The properties of agroecosystems. Agricultural systems, v. 24, n. 2, p. 95-117, 1987.

COSTA, J. S.; BASTOS, G. M. F.; LIMA, B. C. C.; DA SILVA FILHO, J. C. L. Inovação social, prazer e sofrimento no trabalho: o caso do Projeto Mandalla no Ceará. Administração Pública e Gestão Social, 6(1), 11-18, 2014.

LIMA, R.V. de; GAMARRA-ROJAS, G. Camponeses e a mandalla no semiárido brasileiro: reflexões sobre sustentabilidade com base em um estudo de caso com abordagem agroecossistêmica. Cadernos de Ciência \& Tecnologia, v. 34, n. 2, p. 161195, 2018.

FARIAS JR., J.X. de. SAIBA MAIS ... Compreendendo o Projeto Mandalla
Ceará. Fortaleza: Governo do Estado do Ceará, 2019.

MALVEZZI, R. Semi-árido: uma visão holística. Brasília: Confea. 2007.

MESIANO, A., \& DIAS, R. A Tecnologia Social como estratégia para o desenvolvimento sustentável: o caso da Mandalla. Artigo apresentado na VII Jornadas Latino-Americanas de Estudos Sociais das Ciências e das Tecnologias ESOCITE, Rio de Janeiro, 2008.

PARMENTIER, S. Scaling-up agroecological approaches: What, why and how. Oxfam-Solidarity, Brussels, p. 472-80, 2014.

PETERSEN, P.; SILVEIRA, L.M.; FERNANDES, G.B.; ALMEIDA, S.G. Método de Análise EconômicoEcológica de Agroecossistemas. Rio de Janeiro, AS-PTA, 2017. 246 p.

RODRIGUES, F. C. Educação e luta pela terra no Brasil: a formação política no movimento dos trabalhadores rurais sem terra. Educação \& Sociedade, v.38, n.138, p. 27-44, 2017.

VAN HAUWEREINREN, S. Manual de Economía Ecológica. Programa de Economía Ecológica. Publicado pelo Instituto de Ecología Política. Santiago de Chile, 1998. 